\title{
The anthropogenic influence on carbonaceous aerosol in the European background
}

\author{
By BARBARA MAY ${ }^{*}$, DIETMAR WAGENBACH ${ }^{1}$, SAMUEL HAMMER ${ }^{1}$, PETER STEIER ${ }^{2}$, \\ HANS PUXBAU M ${ }^{3}$ and C A S IM IRO PIO ${ }^{4},{ }^{1}$ Institut für Umweltphysik, Universität Heidelberg, Germany; \\ ${ }^{2}$ VERA laboratory, University of Vienna, Austria; ${ }^{3}$ Institute for Chemical Technologies and Analytics, Vienna \\ University of Technology, Austria; ${ }^{4}$ CESAM \& Department of Environment, University of Aveiro, Portugal
}

(Manuscript received 15 January 2008; in final form 28 August 2008)

\begin{abstract}
To constrain the relatively uncertain anthropogenic impact on the organic aerosol load, radiocarbon analyses were performed on aerosol samples, collected year-round, at six non-urban sites including a maritime background and three remote mountain stations, lying on a west-east transect over Western Europe. From a crude three component model supported by TOC and levoglucosan filter data, the fossil fuel, biomass burning and biogenic TOC fraction are estimated, showing at all stations year-round, a relatively constant fossil fuel fraction of around (26 \pm 6$) \%$, a dominant biogenic contribution of on average $(73 \pm 7) \%$ in summer and the continental as well as the maritime background TOC to be only about $50 \%$ biogenic. Assuming biomass burning as completely anthropogenic, the carbonaceous aerosol concentration at the mountain sites was found to have increased by a factor of up to $(1.4 \pm 0.2)$ in summer and up to $(2.5 \pm 1.0)$ in winter. This figure is significantly lower, however, than the respective TOC change since pre-industrial times seen in an Alpine ice core. Reconciling both observations would require an increase, since pre-industrial times, of the background biogenic aerosol load, which is estimated at a factor of 1.3-1.7.
\end{abstract}

\section{Introduction}

The tropospheric aerosol exhibits a net cooling impact on Earth's climate, but to quantify the anthropogenic induced radiative forcing of the different aerosol components, their increase since pre-industrial times or the man-made contribution to the recent aerosol burden has to be known (Ramanathan et al., 2001). For $\mathrm{SO}_{4}^{2-}$, the increase since onset of industrialisation is relatively well settled regarding both deposition and emission changes (Fischer et al., 1998; Fagerli et al., 2007; Vestreng et al., 2007). The largely unknown anthropogenic contribution to the carbonaceous aerosol fraction may eventually be quantified through compilation and modelling of the related emission changes and transformation processes (e.g. Liousse et al., 1996), from ice core studies (Yalcin and Wake, 2002; Legrand et al., 2007) or through investigation of the radiocarbon $\left({ }^{14} \mathrm{C}\right)$ signature of present aerosol samples (Currie et al., 1983).

Most ${ }^{14} \mathrm{C}$ studies on organic aerosol span a relatively short time interval and a small area (with the exception of Schichtel et al., 2008 and Gelencsér et al., 2007, considering a vast area within the US and Western Europe, respectively) and basically

\footnotetext{
*Corresponding author.

e-mail: barbara.may@iup.uni-heidelberg.de

DOI: $10.1111 /$ j.1600-0889.2008.00379.x
}

use the radiocarbon signature to separate fossil and contemporary source contributions, assuming emissions from the contemporary living biosphere to be tagged by the well-known radiocarbon content of current atmospheric $\mathrm{CO}_{2}$, whereas fossil fuels are ${ }^{14} \mathrm{C}$-free (Currie et al., 1989; Klinedinst and Currie, 1999; Lemire et al., 2002; Bench, 2004; Lewis et al., 2004; Szidat et al., 2004a,b; Tanner et al., 2004). These two source component studies present the so called contemporary carbon fraction $f_{\mathrm{C}}$, which corrects the measured ${ }^{14} \mathrm{C}$ concentration for the contemporary enhancement of the atmospheric ${ }^{14} \mathrm{C}$ content remaining from the nuclear bomb-peak in the early 1960s. The $f_{\mathrm{C}}$ values, which have been obtained mostly in urban/suburban areas and over short sampling periods, show strong variations ranging from $27 \%$ up to $80 \%$ in summer and $16 \%$ to $64 \%$ in winter. This approach, however, does not consider that the significant biomass burning contribution may be tagged by a certain bomb ${ }^{14} \mathrm{C}$ integrating signature, which is, in case of wood burning, significantly larger than the present-day atmospheric $\mathrm{CO}_{2}$ one. Hildemann et al. (1994), Ward et al. (2006), Zencak et al. (2007) and Szidat et al. (2007) tried to tackle the problem of this over-contemporary aerosol contribution by discerning the fossil carbon fraction from a so-called biomass fraction, denoting a composite of biomass burning and contributions from the living biosphere. Finally, Szidat et al. (2006) and Gelencsér et al. (2007) attempted to improve the distinction of more than two 
different carbonaceous aerosol fractions using ${ }^{14} \mathrm{C}$ analysis. In any case, the two source component approach does not allow to infer the entire anthropogenic contribution to the carbonaceous aerosol since the biomass burning contribution cannot be quantified on its own.

Aiming to constrain the anthropogenically induced fraction of present carbonaceous aerosol, we report on the ${ }^{14} \mathrm{C}$ measurements of carbonaceous aerosol filters collected weekly from 2002 to 2004 at six relatively remote sites over Western Europe (EU-CARBOSOL project, Legrand and Puxbaum, 2007). In this context, radiocarbon analyses were made on specifically selected aerosol samples and evaluated by a crude three component model, which considers fossil fuel, biomass burning and biogenic contributions.

A ${ }^{14} \mathrm{C}$ supported study of the CARBOSOL aerosol samples has been already performed by Gelencsér et al. (2007), but focuses on the detailed source apportionment of total organic carbon (TOC) at the different sites, including elemental carbon (EC) as well as primary and secondary organic carbon (OC); (for details on the extension of ${ }^{14} \mathrm{C}$ analyses with respect to Gelencsér et al., 2007, see 2.3 Sampling selection for ${ }^{14} \mathrm{C}$ analyses).

Here we will address the specific limitations in attempting to derive a representative figure on the anthropogenic versus natural share of the present European TOC aerosol body via ${ }^{14} \mathrm{C}$ analyses. Thereby emphasis is on the remote CARBOSOL sites, which are less directly influenced by local emissions.

\section{Method}

\subsection{Sampling}

Focusing on rural and remote sites, CARBOSOL aerosol filter samples were taken at six sampling stations lying on a west-east transect over Western Europe (Fig. 1). The quartz-filter samples were taken weekly for $2 \mathrm{yr}$ from 2002 to 2004 and analysed for various inorganic and organic aerosol components, including TOC (OC, EC), (Pio et al., 2007), the transport tracer ${ }^{210} \mathrm{~Pb}$ (Hammer et al., 2007) and the biomass burning tracer levoglucosan (Levo), (Puxbaum et al., 2007).

For TOC and levoglucosan (used to infer the biomass burning fraction), the detection limit is given as three times the standard deviation of the filter blank, being $30-90 \mathrm{ng} \mathrm{m}^{-3}$ for TOC (Pio et al., 2007) and less than $1 \mathrm{ng} \mathrm{m}^{-3}$ for levoglucosan (Puxbaum et al., 2007). These values are equivalent to an average relative uncertainty for the here deployed figures of up to $10 \%$ for Aveiro (AVE), Puy de Dôme (PDD), Schauinsland (SIL) and K-Puzta (KPZ) and 30-40\% for Azores (AZO) and Sonnblick (SBO). Additional uncertainties arise from an inhomogeneous distribution of the organic matter over the filter, incomplete detection of TOC or disturbance of levoglucosan measurements by other chemical components like arabitol (Puxbaum et al., 2007). However, the data evaluation described in 3.1 proofs mostly insensitive to the uncertainty of TOC and levoglucosan, therefore, assuming a relative error of $10 \%$ for both components is deemed sufficient enough even for the background stations.

\subsection{Radiocarbon analysis}

We analysed (after removing the inorganic carbon fraction) the ${ }^{14} \mathrm{C}$ content of total organic carbon, here defined as $\mathrm{TOC}=$ $\mathrm{OC}+\mathrm{EC}$, rather than separating the organic carbon (OC) and elemental carbon (EC) fraction as done by Szidat et al. (2006). Radiocarbon values are given as $p m C=\left(\frac{\Delta^{14} \mathrm{C}}{1000}+1\right) \times 100[\%]$ (percent modern Carbon), which gives the radiocarbon concentration relative to the oxalic acid standard concentration of 1950 , corrected for isotope fractionation according to Stuiver and Polach (1977). Complying with most publications on ${ }^{14} \mathrm{C}$ analysis of carbonaceous aerosol, we report measured radiocarbon values as $f_{\mathrm{m}}=p m C / 100$, that is fraction modern (carbon), where 'modern' refers by definition to the standard value of 1950.

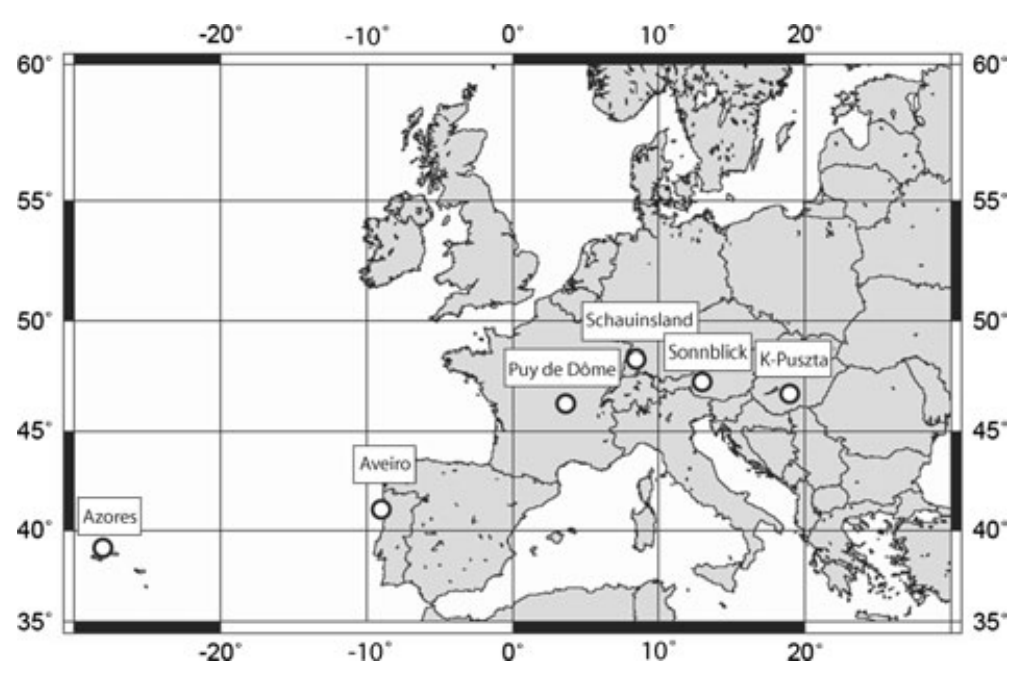

Fig. 1. Map of the CARBOSOL sampling network over Western Europe: Azores (AZO, Portugal): maritime background; Aveiro (AVE, Portugal); ground-level, rural site; Puy de Dôme (PDD, France): medium-elevated site on an isolated mountain peak; Schauinsland (SIL, Germany): medium-elevated site on a mountain ridge in a biogenic environment; Sonnblick (SBO, Austria): high Alpine mountain site, continental background; K-Puszta (KPZ, Hungary): ground-level, continental site. 
Filter aliquots corresponding to 250 to $850 \mathrm{~m}^{3}$ air were combusted and purified in a stream of pure oxygen at $900^{\circ} \mathrm{C}$ in a specifically designed system (CARMEN). The graphitisation and accelerated mass spectrometer (AMS) measurement performed at the VERA laboratory in Vienna yields a blank contribution of typically $0.5 \mu \mathrm{gC}$ with a ${ }^{14} \mathrm{C}$ signature of around $f_{\mathrm{m}}=0.4$ (Steier et al., 2006).

The CARMEN relevant system blank of $(64 \pm 8) \mu \mathrm{gC}$ shows $\mathrm{a}^{14} \mathrm{C}$ signature of $(0.81 \pm 0.03)$. Additionally, filter blanks (including treatment in the field) were measured and contribute with a varying blank between 0.56 and $7.52 \mu \mathrm{gC} \mathrm{cm}^{-2}$, depending on the sampling location and pre-treatment of the filters (outlined by Pio et al. (2007)). The ${ }^{14} \mathrm{C}$ signature of this filter blank contribution ranged between 0.29 and 0.88 .

The relative overall uncertainty of the measured radiocarbon values is thus less than $3 \%$ for sample masses larger than $500 \mu \mathrm{gC}$. Only the background filter pools had smaller carbon masses leading to a relative error of up to $8 \%$. We consider this uncertainty to be sufficiently small since the investigated seasonal and large-scale spatial variations are much larger.

\subsection{Sample selection for ${ }^{14} \mathrm{C}$ analyses}

For the purpose of this study, the main catchment area of the air mass reaching the sampling station is of special interest in view of the natural and anthropogenic sources involved. Due to the weekly collection period it is rather difficult to gain a clear picture on the characteristic up wind source areas, for example, by back trajectory analyses. We selected the weekly samples therefore according to Hammer et al. (2007) through their coregistered atmospheric ${ }^{210} \mathrm{~Pb}$ activity, reflecting the influence of continental air mass during the sampling period.

Except for the maritime background site Azores, filters for ${ }^{14} \mathrm{C}$ analysis were selected as to obtain, as far as possible, representative means for the summer (May-Sep) and winter (Nov-Mar) periods, respectively. Out of these seasonal distinguished sample inventories at each site, primarily those filters were used, which ${ }^{210} \mathrm{~Pb}$ activity were significantly above the site specific mean. According to the ${ }^{210} \mathrm{~Pb}$ climatologies of the CARBOSOL sites investigated by Hammer et al. (2007), this criteria should ensure a distinct and comparable influence of large-scale continental TOC emission sources seen within both seasons at the different sites. In this study, the synoptical scale of ${ }^{210} \mathrm{~Pb}$ variability (i.e. weekly to bi-weekly) was shown to coincide particularly with organic carbon suggesting that a good part of the OC variability is governed by air mass transport patterns (i.e. imprint of large-scale continental emission sources) rather than temporal emission changes. Furthermore, clear outliers with respect to chemical species (mostly TOC and Levo) are discarded.

Different from this selection procedure, two background composite samples were produced: (1) a maritime background mean selected from the Azores independent of season and the ${ }^{210} \mathrm{~Pb}$ activity by considering only those filters sampled under per- sistent sea wind conditions and (2) a continental background composite made up by Sonnblick winter filters with relatively low ${ }^{210} \mathrm{~Pb}$ values. It is assumed that the high Alpine site SBO should be effectively decoupled from ground level air during that condition, thus providing a representative large-scale mean of the continental winter free troposphere.

The thus obtained sample pools included 5-10 weekly samples from which aliquots were combusted together to give the respective mean ${ }^{14} \mathrm{C}$ values.

For the mean ${ }^{14} \mathrm{C}$ values of the ground level sites AVE and KPZ, shown here for illustrative purpose only, we used the identical data already reported in Gelencsér et al. (2007). Also the continental background mean is based on the same measurement as deployed in Gelencsér et al. (2007), though slightly revised by an improved blank correction (being most relevant for this low-mass TOC samples) resulting in a $6 \%$ smaller $f_{\mathrm{m}}$ value.

We preferred not to include the previous ${ }^{14} \mathrm{C}$ data of SIL, PDD and SBO (summer) used in Gelencsér et al. (2007) in our extended study since these few single filter measurements have been not as uniformly selected (previously focussing on simultaneous samples at PDD and SIL as well). Although there is no dramatic difference between the respective old and new ${ }^{14} \mathrm{C}$ means (except for the winter $f_{\mathrm{m}}$ values at PDD and SIL, where the new pool filter values are $16 \%$ larger and $7 \%$ smaller, respectively, than the old three filters composites), we choose to base the present study solely on the more representative filter pool measurements.

\section{Results}

\subsection{Data evaluation}

The blank corrected radiocarbon data of the selected CARBOSOL filter pools are reported in Table 1 as $f_{\mathrm{m}}$ values together with the respective mean TOC and ${ }^{210} \mathrm{~Pb}$ values.

By definition $f_{\mathrm{m}}$ refers to the ${ }^{14} \mathrm{C}$ content of atmospheric $\mathrm{CO}_{2}$ in 1950. Thus, the quantification of the fossil (i.e. entirely anthropogenic) versus non-fossil (natural as well as anthropogenic) TOC fraction from $f_{\mathrm{m}}$ values is complicated by the bomb ${ }^{14} \mathrm{C}$ mainly released in the early 1960 's. As a result of this ${ }^{14} \mathrm{C}$ contamination of the atmospheric $\mathrm{CO}_{2}$ and the related biospheric reservoir, natural emissions from the living biosphere are marked by the (declining) present-day ${ }^{14} \mathrm{CO}_{2}$ level. However, burning of biomass, especially when some 10 years old, would provide carbon emissions with a significantly higher ${ }^{14} \mathrm{C}$ level compared to the contemporary living biosphere.

This fact provides the prime reason, why the non-fossil TOC needs to be split in a contemporary biogenic and a biomass burning fraction. The respective three component approach, including now fossil fuel (ff), biomass burning (bb) and biogenic contributions (bio) from the living biosphere gives the mass balance $T O C=(T O C)_{\mathrm{ff}}+(T O C)_{\mathrm{bb}}+(T O C)_{\mathrm{bio}}$ along with the 
Table 1. The blank-corrected ${ }^{14} \mathrm{C}$ concentrations of analysed filter pools ( $N=$ number of weekly filters in sample composite), at the CARBOSOL stations $(\mathrm{AZO}=$ Azores, AVE $=$ Aveiro, $\mathrm{PDD}=$ Puy de Dôme, $\mathrm{SIL}=$ Schauinsland, $\mathrm{SBO}=$ Sonnblick, $\mathrm{KPZ}=\mathrm{K}$-Puszta), with $f_{m} S D$ including uncertainties as well as blank variations. Given along are respective mean values of TOC $\left({ }^{*} \pm 9-12 \%\right)$, and ${ }^{210} \mathrm{~Pb}\left({ }^{* *} \pm 10 \%\right)$.

\begin{tabular}{lccccc}
\hline Site & $\begin{array}{c}\text { Temporal } \\
\text { coverage }\end{array}$ & $N$ & $\begin{array}{c}{ }^{210} \mathrm{~Pb}^{*} \\
\left(\frac{m B q}{m^{3}}\right)\end{array}$ & $\begin{array}{c}\mathrm{TOC}^{* *} \\
\left(\mathrm{ngC} \mathrm{m}^{-3}\right)\end{array}$ & $f_{m}$ \\
\hline AVE & Dec-Feb & 9 & 0.64 & 14070 & $0.921 \pm 0.009$ \\
& May-Aug & 9 & 0.63 & 3560 & $0.772 \pm 0.006$ \\
PDD & Dec-Feb & 5 & 0.21 & 600 & $0.721 \pm 0.011$ \\
& May-Aug & 5 & 0.73 & 4380 & $0.867 \pm 0.013$ \\
SIL & Jan-Feb & 5 & 0.67 & 2650 & $0.731 \pm 0.006$ \\
& May-Seb & 6 & 0.89 & 4890 & $0.856 \pm 0.006$ \\
SBO & Dec-Mar & 9 & 0.31 & 400 & $0.835 \pm 0.030$ \\
& Jun-Sep & 6 & 0.58 & 1380 & $0.794 \pm 0.018$ \\
KPZ & Nov-Feb & 9 & 0.93 & 10650 & $0.784 \pm 0.006$ \\
& May-Seb & 10 & 0.86 & 6040 & $0.873 \pm 0.012$ \\
& & & Background & & \\
AZO & Maritim & 5 & n.a. & 220 & $0.726 \pm 0.022$ \\
SBO & Continental & 9 & 0.14 & 240 & $0.678 \pm 0.044$ \\
\hline
\end{tabular}

isotope mass balance equation

$$
\begin{aligned}
T O C \times f_{\mathrm{m}}= & (T O C)_{\mathrm{ff}} \times f_{\mathrm{ff}} \\
& +(T O C)_{\mathrm{bb}} \times f_{\mathrm{bb}}+(T O C)_{\mathrm{bio}} \times f_{\mathrm{bio}},
\end{aligned}
$$

where the $f$ values on the right hand side denote the actual ${ }^{14} \mathrm{C}$ signature of the three TOC fractions. As TOC and $f_{\mathrm{m}}$ are the only directly measured quantities, there are still five parameters, which need to be estimated indirectly.

The fossil fuel component is eliminated as $f_{\mathrm{ff}}=0$. For $f_{\text {bio }}$ we assume the ${ }^{14} \mathrm{C}$ content of TOC emitted by the living biosphere, which can be set equal to the atmospheric ${ }^{14} \mathrm{CO}_{2}$ (Levin and Kromer, 2004), being on average 1.07 during the CARBOSOL sampling period.

The biomass burning ${ }^{14} \mathrm{C}$ signature $f_{\text {bb }}$ may span a relatively large range depending on the age of combusted material. The minimum value referring to young biomass matter not older than one or $2 \mathrm{yr}$ (e.g. as released from burning of agricultural waste) should be still close to the biogenic value of 1.07. The maximum value is given by the radiocarbon signature of emissions associated with burning of wood (or related items), provided that its growing period is well within the bomb era. Hildemann et al. (1994) reported an upper value of 1.29 for $40 \mathrm{yr}$ old softwood trees harvested in 1985. More recent studies from Klinedinst and Currie (1999) and Zencak et al. (2007) measured values up to 1.23, while Lewis et al. (2004) calculated an upper limit of 1.25 for softwood trees. To gain a precise $f_{\mathrm{bb}}$ value, the age composition of the burned biomass would be needed for the different stations and seasons. Lacking this information we simply de- ploy the average of the minimum and the maximum $f_{\mathrm{bb}}$ value by Lewis et al. (2004) being (1.16 \pm 0.09$)$, where the uncertainty covers the whole range of $f_{\mathrm{bb}}$.

To estimate $(T O C)_{\mathrm{bb}}$ we use levoglucosan (Levo), a tracer for cellulose pyrolysis (Simoneit et al., 1999), to quantify the biomass burning particulate $\mathrm{OC}$ fraction $(O C)_{\mathrm{bb}}$, which is then related to $(E C)_{\mathrm{bb}}$. The biomass burning fraction is calculated using the emission factors $(O C / \text { Levo })_{\mathrm{bb}}$ and $(E C / O C)_{\mathrm{bb}}$ as:

$(T O C)_{\mathrm{bb}}=(\text { Levo })_{\text {meas }} \times\left(\frac{O C}{\text { Levo }}\right)_{\mathrm{bb}} \times\left(1+\left(\frac{E C}{O C}\right)_{\mathrm{bb}}\right)$.

Respective emission factors are discussed by Puxbaum et al. (2007), from where we here adopt $(\text { OC } / \text { Levo })_{\mathrm{bb}}=7.35$ and $(O C / E C)_{\mathrm{bb}}=6$. Although these factors can vary depending on tree types and combustion characteristics (Bond et al., 2004; Puxbaum et al., 2007), we do not try to appoint different values for the different stations and seasons, considering the large variability reported in the literature for these factors and instead assume for both input parameters a relative uncertainty of $50 \%$.

The relative biogenic contribution $\frac{(T O C)_{\text {bio }}}{T O C}$ can be now calculated from the isotope mass balance as:

$$
\frac{(T O C)_{\mathrm{bio}}}{T O C}=\frac{f_{\mathrm{m}}}{f_{\mathrm{bio}}}-\frac{(T O C)_{\mathrm{bb}}}{T O C} \times \frac{f_{\mathrm{bb}}}{f_{\mathrm{bio}}}
$$

Since the analytical errors of all three TOC fractions as derived by error propagation are mainly governed by the uncertainties of $(O C / \text { Levo })_{\mathrm{bb}}$ and $(O C / E C)_{\mathrm{bb}}$ (and in the case of small sample mass by the uncertainty of TOC), the relatively large errors for $(T O C)_{\mathrm{ff}},(T O C)_{\mathrm{bb}}$ and $(T O C)_{\text {bio }}$ displayed in Fig. 2 are mostly

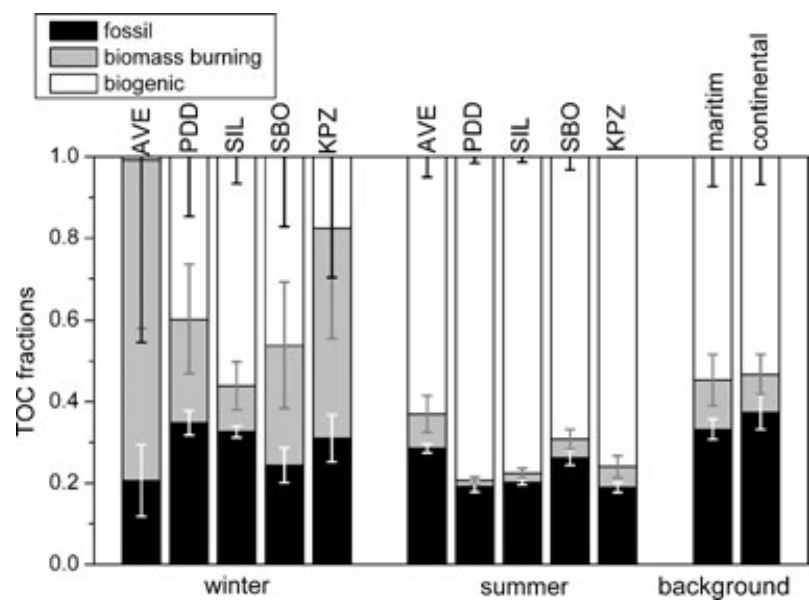

Fig. 2. Fossil fuel, biomass burning and biogenic TOC fractions at the CARBOSOL stations $(\mathrm{AVE}=$ Aveiro; $\mathrm{PDD}=$ Puy de Dôme; $\mathrm{SIL}=$ Schauinsland; $\mathrm{SBO}=$ Sonnblick; $\mathrm{KPZ}=\mathrm{K}$-Puszta, maritime $=$ Azores; continental Sonnblick; free troposphere conditions) in summer and in winter. The error bars (white $=$ fossil fuel; light grey $=$ biomass burning black $=$ biogenic) as calculated by error propagation are dominated by the emission factors uncertainties. 
due to the badly known emission factors rather than from measurement uncertainties.

\subsection{Overview on fossil fuel, biomass burning and biogenic TOC fraction}

Figure 2 shows the relative fossil fuel, biomass burning and biogenic fraction of TOC with their analytical errors. Considering the weekly sampling of the filters pool measurements and the large catchment area, the derived TOC fractions are expected to reflect the integrated TOC source mix as seen at remote, nonurban sampling sites in Western Europe. One should keep in mind that the TOC concentrations at the two ground level stations AVE and KPZ are, due to their closer proximity to TOC sources, by an order of magnitude higher than at the remote mountain sites. Furthermore, the maximum TOC concentrations at the ground level stations occur in winter, while the three mountain sites PDD, SIL and SBO have their maximum in summer (Pio et al., 2007), which is basically due to the reduced vertical mixing intensity in the atmosphere in winter (Hammer et al., 2007). In the following, we address the spatial and seasonal variation of the different TOC fractions at the CARBOSOL sites by calculating mean values and standard deviations. In addition to this natural variation, the mean analytical uncertainty [in square brackets] reflects the precision of the estimate.

We find that the fossil fuel fraction is with $(26 \pm 6) \%$ $[ \pm 3 \%]$ rather constant over the five sampling sites throughout the year. In summer the biogenic fraction dominates with $(73 \pm 7) \%[ \pm 3 \%]$, also not changing very much from site to site, while in winter the biomass burning fraction has a large share in the TOC composition, with up to a mean $(22 \pm 10) \%[ \pm 12 \%]$ for the mountain site stations and $(65 \pm 19) \%[ \pm 34 \%]$ for the ground level stations. This large contribution of $(T O C)_{\mathrm{bb}}$ at the low-level stations can be explained by a high contribution from wood burning for heating, which is still common especially in Portugal (Pio et al., 2007). The background carbonaceous aerosol contains with $(46 \pm 1) \%[ \pm 7 \%]$ a relatively high nonbiogenic TOC component. Here it is interesting to note, that the maritime (AZO) and the continental (SBO) background sites reveal virtually the same source composition including a rather high fossil fuel fraction. This observation might be due to a common influence of trans-continental pollution transport.

The present values obtained differ from the data of Gelencsér et al. (2007) only regarding the relative non-fossil contributions in winter at the mountain sites, since for PDD and SIL more representative sample pools have been used and an additional winter value (no background conditions) for SBO was obtained.

The ${ }^{14} \mathrm{C}$ supported study by Szidat et al. (2006) of urban aerosol at Zurich (Switzerland) are quantitatively in agreement with our findings in reporting a relatively constant fossil fraction independent of season $\left(\frac{(O C)_{\mathrm{ff}}}{O C}=(32 \pm 8) \%\right)$, but a dominant biogenic fraction during summer $\left(\frac{(O C)_{\text {bio }}}{O C}=(60 \pm 10) \%\right)$ in contrast to a substantial biomass burning fraction during winter $\left(\frac{(O C)_{\text {bb }}}{O C}=(41 \pm 7) \%\right)$.

The winter data of our two low-level sites Aveiro and K-Puszta show a quite similar pattern to the study of Szidat et al. (2007) performed during winter at two (urbanised) Alpine valley floors. Here, the authors attributed the very large non-fossil fraction of total organic matter (total OC by mass) of up to $88 \%$ to the dominating influence of residential wood burning. It is evident, however, that these ground level findings reflect the very local conditions (especially during low-mixing episodes in winter). They are thus not relevant for the purpose of our present study.

Overall we conclude that $(T O C)_{\mathrm{ff}}$ contributes year round significantly at all CARBOSOL sampling sites and seems homogeneously distributed, which might be due to an homogeneous fossil fuel emission source and possibly due to a longer residence time of $(T O C)_{\mathrm{ff}}$ in the atmosphere. A similar homogeneous source distribution might be concluded for the biogenic TOC fraction in summer. In winter biomass burning strongly influences the TOC load at the low-level stations. Both the maritime and the continental background TOC is to only about $50 \%$ made up by biogenic emissions.

\subsection{Anthropogenic contribution to TOC}

To determine the anthropogenically driven increase in TOC, we must define the anthropogenic versus natural components of the carbonaceous aerosol within the investigated area. Both fractions encompass a mix of different sources. Natural TOC contributions are confined to biogenic emissions from the living biosphere as well as wild forest fires in summer. Specifically in Western Europe the main anthropogenic TOC contributions arise from combustion of fossil fuel, wood burning (for heating in winter) and from agricultural waste burning (mostly in spring and autumn). Also agricultural biomass for fuel production and biogenic emissions due to agriculture may add to the anthropogenic TOC fraction. More over an additional albeit indirect man-made TOC contribution follows from an anthropogenically caused increase in the atmospheric oxidant level resulting in an enhanced secondary organic aerosol (SOA) production from mostly biogenic gas precursors (Limbeck et al., 2003; Tsigaridis et al., 2006).

We simplify these rather complicated figures by defining the increase in the air-borne TOC concentration due to anthropogenic contribution by the increase factor $F^{\text {ant }}$ given as:

$F^{\mathrm{ant}}=\frac{(T O C)}{(T O C)_{\mathrm{bio}}^{\mathrm{nat}}+(T O C)_{\mathrm{bb}}^{\mathrm{nat}}}$

In the following, all TOC fractions with one index (ff/bb/bio) indicate the respective total TOC fraction irrespective of anthropogenic and natural origin, while a second index (nat/ant) defines if the TOC component is naturally or anthropogenically induced. 
Table 2. Anthropogenic increase factor $F^{\text {ant }}$ (according to eq. 4) for the atmospheric TOC concentration assuming biogenic TOC to be completely natural $(T O C)_{\mathrm{bio}}^{\mathrm{nat}}=(T O C)_{\mathrm{bio}}$ and $(\mathrm{a})(T O C)_{\mathrm{bb}}^{\mathrm{nat}}=(T O C)_{b b}$, that is, only fossil fuel combustion as anthropogenic source or (b) $(T O C)_{\mathrm{bb}}^{\mathrm{nat}}=0$, that is, both fossil fuel combustion and biomass burning as anthropogenic TOC contributions. Values with a strong local biomass burning contribution are not reported.

\begin{tabular}{lccc}
\hline Site & $\begin{array}{c}\text { Temporal } \\
\text { coverage }\end{array}$ & $\begin{array}{c}F_{\mathrm{ant}} \\
(\text { TOC })_{\mathrm{bb}}^{\mathrm{nat}}=(\text { TOC })_{\mathrm{bb}}\end{array}$ & $(\text { TOC })_{b b}^{\mathrm{nat}}=0$ \\
\hline AVE & Dec-Feb & - & - \\
& May-Aug & $1.4 \pm 0.2$ & $1.6 \pm 0.3$ \\
PDD & Dec-Feb & $1.5 \pm 0.5$ & $2.5 \pm 1.0$ \\
& May-Aug & $1.2 \pm 0.2$ & $1.3 \pm 0.2$ \\
SIL & Jan-Feb & $1.5 \pm 0.3$ & $1.8 \pm 0.4$ \\
& May-Seb & $1.3 \pm 0.3$ & $1.3 \pm 0.2$ \\
SBO & Dec-Mar & $1.3 \pm 0.4$ & $2.2 \pm 0.9$ \\
& Jun-Sep & $1.4 \pm 0.2$ & $1.4 \pm 0.2$ \\
KPZ & Nov-Feb & - & - \\
& May-Seb & $1.2 \pm 0.2$ & $1.3 \pm 0.2$ \\
& & Background & \\
AZO & Maritim & $1.5 \pm 0.3$ & $1.8 \pm 0.4$ \\
SBO & Continental & $1.6 \pm 0.3$ & $1.9 \pm 0.4$ \\
\hline
\end{tabular}

Simply assuming $(T O C)_{\text {bio }}$ to be totally natural, thus equal to $(T O C)_{\text {bio }}^{\text {nat }}$ (neglecting agricultural activities and man-made influences on SOA production) and $(T O C)_{\mathrm{bb}}$ being totally anthropogenic, i.e. $(T O C)_{\mathrm{bb}}^{\mathrm{nat}}=0$ (neglecting wild fires), the increase factor $F^{\text {ant }}$ reduces to $\frac{T O C}{(T O C)_{\text {bio }}}$, which is the inverse of the actually observed biogenic TOC fraction. For illustrative purpose the anthropogenic increase factor is given in Table 2 for all CARBOSOL sampling stations, though only relevant for the remote sites.

At the remote mountain sites, which are more isolated from direct emission sources and thus should reflect the overall aerosol composition over Western Europe the best, we find an anthropogenic increase in TOC due to fossil fuel and biomass burning contributions by a factor of $(1.8 \pm 0.4)$ to $(2.5 \pm 1.0)$ in winter and $(1.3 \pm 0.2)$ to $(1.4 \pm 0.2)$ in summer. The continental background value at SBO lies with $(1.9 \pm 0.4)$ between the winter and the summer value.

Investigating the uncertainty arising from the attribution of biomass burning as completely anthropogenic, we find that in summer, when natural forest fires might contribute significantly, $(T O C)_{b b}$ is low, while in winter natural fires are infrequent in Europe. In addition, as most large natural forest fires (induced by lightning) occur in areas, where no fire-management is carried out (Stocks et al., 2003), it is reasonable to neglect natural forest fires in the densely populated area of Western Europe (Bond et al., 2004). Still, redefining the biomass burning fraction as totally natural, i.e. $(T O C)_{\mathrm{bb}}^{\mathrm{nat}}=(T O C)_{\mathrm{bb}}$ (see Table 2$)$, would result in an increase factor of $(1.2 \pm 0.2)$ to $(1.6 \pm 0.3)$, which would be a reduction of $40 \%$ at the most.
Regarding $T O C_{\text {bio }}$ we have no information on its natural versus anthropogenic composition, which puts a significant uncertainty on $F^{\text {ant }}$, especially considering the possibility of an indirectly man-made contribution from increased oxidant levels. There are however investigations regarding the increase of the TOC aerosol since pre-industrial times, which might help to estimate the anthropogenic contribution to $(T O C)_{\text {bio }}$.

Kanakidou et al. (2000) modelled an increase of the SOA formation rate from naturally emitted biogenic compounds by a factor of 3-4 due to a human activities induced increase of the atmospheric oxidant level. Tsigaridis et al. (2006) modelled the rise of the global atmospheric aerosol TOC load since preindustrial times including this increased anthropogenic SOA production as well as a faster conversion of hydrophobic to hydrophilic carbonaceous aerosol leading to higher removal rates. They reported for TOC including fossil fuel, biomass burning and biogenic sources, a temporal increase by a factor of $F^{\text {time }}=\frac{(T O C)^{\text {present }}}{(T O C)^{\text {pre-ind }}}=1.6$ since pre-industrial times. The increase of the atmospheric SOA concentration alone was estimated at 1.2. However, as the organic aerosol is modelled on a global scale and underestimates measured organic aerosol values by a factor of two, a direct comparison with our ${ }^{14} \mathrm{C}$ factor would be not conclusive.

Jenk et al. (2006) reports measurements of filterable TOC concentrations and respective ${ }^{14} \mathrm{C}$ analyses on an Alpine ice core from Fiescherhorn glacier, showing an increase of this particulate fraction by a factor of $F^{\text {time }}=3.5$ from pre-industrial times to 1940 . However these data are also not comparable to our estimates as the water-soluble fraction is not included.

Legrand et al. (2007) appraise the atmospheric TOC concentrations from measurements on an Alpine ice core (Col du Dôme) by adding the filterable, that is, water-insoluble TOC fraction and the water-soluble TOC fraction, which is estimated by subtracting organics related to gas solubilisation in precipitation (mainly monocarboxylic acids) from measured dissolved organic carbon (DOC) concentrations. This estimate gives an atmospheric TOC increase in the early 1970 s since pre-industrial times by a factor $F^{\text {time }}=2.5$.

This finding of Legrand et al. (2007) should be most comparable to our increase factor from the high Alpine site SBO and might be used to constrain the increase of $(T O C)_{\text {bio }}$ since pre-industrial times. Assuming $(T O C)^{\text {pre-ind }}=(T O C)_{b i o}^{\text {pre-ind }}+$ $(T O C)_{b b}^{\text {pre-ind }}$ and $(T O C)^{\text {present }}=T O C$, the increase of $(T O C)_{\text {bio }}$ is derived by

$$
\frac{(T O C)_{\mathrm{bio}}}{(T O C)_{\mathrm{bio}}^{\mathrm{pre}-\mathrm{ind}}}=\frac{F^{\mathrm{time}} \times(T O C)_{\mathrm{bio}}}{(T O C)-F^{\mathrm{time}} \times(T O C)_{\mathrm{bb}}^{\mathrm{pre}-\mathrm{ind}}}
$$

Using $F^{\mathrm{time}}=2.5$ and depending whether $(T O C)_{\mathrm{bb}}^{\mathrm{pre}-\text { ind }}=0$ or $(T O C)_{\mathrm{bb}}^{\text {pre-ind }}=(T O C)_{\mathrm{bb}}$, that is, how the biomass burning fraction evolved over time, Table 3 shows the increase of $(\text { TOC })_{\text {bio }}$ since pre-industrial times.

At SBO, we find an increase of $(T O C)_{\text {bio }}$ between 1.2 to 4.4 in winter and 1.3 to 1.7 for continental background conditions. 
Table 3. Increase in the biogenic TOC fraction since pre-industrial times (according to eq. 5) assuming a total increase of TOC by a factor of $F^{\text {time }}=2.5$ (derived from ice core data Legrand et al., 2007) and (a) $(T O C)_{\mathrm{bb}}^{\mathrm{pre}-\mathrm{ind}}=0$, i.e. no biomass burning in pre-industrial times or (b) $(T O C)_{\mathrm{bb}}^{\mathrm{pre}-\mathrm{ind}}=(T O C)_{\mathrm{bb}}$, i.e. no increase in biomass burning since pre-industrial times. Unreasonable values due to strong biomass burning contribution are not reported.

\begin{tabular}{lccc}
\hline Site & Temporal & \multicolumn{2}{c}{$\frac{(\text { TOC })_{\text {bio }}}{(T O C)_{\text {bio }}^{\text {pe- }}}$} \\
\cline { 2 - 4 } & coverage & $(\mathrm{a})$ & (b) \\
\hline AVE & Dec-Feb & - & - \\
& May-Aug & 1.6 & 2.0 \\
PDD & Dec-Feb & 1.0 & 2.7 \\
& May-Aug & 2.0 & 2.1 \\
SIL & Jan-Feb & 1.4 & 2.0 \\
& May-Seb & 1.9 & 2.1 \\
SBO & Dec-Mar & 1.2 & 4.4 \\
& Jun-Sep & 1.7 & 2.0 \\
KPZ & Nov-Feb & - & - \\
& May-Seb & 1.9 & 2.2 \\
& Background & & 2.0 \\
AZO & Maritim & 1.4 & 1.7 \\
\hline
\end{tabular}

In summer, when the biogenic source dominates, the increase lies between a factor of 1.7 and 2.0.

Discussing the two limiting scenarios for $(T O C)_{\mathrm{bb}}^{\mathrm{pre}-\mathrm{ind}}$, we find that assuming no biomass burning in pre-industrial times is surely wrong as cultural development over the last $6000 \mathrm{yr}$ involved biomass burning for slashing-and-burning and for heating (Carcaillet et al., 2002), hence a lower limit for the increase in biogenic TOC is obtained here. On the other hand, assuming biomass burning TOC concentrations to be the same in preindustrial and present times would disregard e.g. the changing use of different bio-fuels for heating and energy production (Bond et al., 2004), decreasing importance of slashing-andburning in Western Europe as well as climate change influencing the frequency and burned area of forest fires (Stocks et al. (2003)), and thus gives an upper limit to the biogenic increase factor.

The increase factor derived by Tsigaridis et al. (2006) for SOA lies at the lower limit of our range. However, this modelled value is estimated for a global scale and might vary strongly with space and time, depending on production and removal rates. The increased production of SOA by a factor of 3-4 proposed by Kanakidou et al. (2000) together with the increased removal rate by a factor of 1.3-1.4 suggested by Tsigaridis et al. (2006) surely allows for a larger increase of the biogenic TOC concentration.

Concluding we find, that at least $37 \%$ (fossil) up to $47 \%$ (fossil and biomass burning) of the European background TOC is of anthropogenic origin. Additionally, if $(T O C)_{\text {bio }}^{\text {pre-ind }}=(T O C)_{\text {bio }}^{\text {nat }}$, that is, $(T O C)_{\text {bio }}^{\text {pre-ind }}$ is natural and constant in time, $25 \%$ to $42 \%$ of the background $(T O C)_{\text {bio }}$ fraction might be anthropogenically induced as well. $(T O C)_{\text {bio }}^{\text {pre-ind }}$ was propably not purely natural as emissions from anthropogenic agriculture contributed already significantly in pre-industrial times, which means the derived anthropogenic $(T O C)_{\text {bio }}$ fraction is only a lower limit.

\section{Conclusions}

There are still a lot of assumptions necessary, to quantify the overall human impact on European carbonaceous aerosol from ${ }^{14} \mathrm{C}$ analyses. However a significant anthropogenic effect cannot be dismissed, since fossil fuel combustion and biomass burning alone already account for an anthropogenic increase of the European continental background TOC seen at SBO by a factor of $(1.9 \pm 0.4)$, which would suggest that up to $47 \%$ of the 'clean air' TOC is man-made. The major obstacle in obtaining useful estimates of the anthropogenic influence on TOC is shown to be the biomass burning fraction, which ${ }^{14} \mathrm{C}$ signature systematically differs from contemporary biogenic emissions and thus needs to be quantified separatly (by chemical tracers). Moreover, the attribution of biomass burning TOC to the man-made or natural category remains uncertain, both temporally and spatially.

Additional, the biogenic TOC fraction cannot be simply attributed as natural (and broadly constant in time), as agriculture, use of bio-fuel and especially the indirect anthropogenic influence on the SOA cycle (by enhanced atmospheric oxidant levels and acidity) must be taken into account. Complying with an increase factor for TOC since pre-industrial times of 2.5 as derived from ice core data, the biogenic TOC fraction of the continental background carbonaceous aerosol, appear to have increased along by a factor of 1.3 to 1.7 . For the continental background, this would correspond to an anthropogenic contribution to the biogenic TOC fraction of at least $25 \%$ to $42 \%$. Although still uncertain, these findings confirm that this indirect manmade perturbation of the natural TOC cycle is quite substantial and calls for thorough investigation. In this context, more ice core analyses of TOC may be crucial in supplementing ${ }^{14} \mathrm{C}$ analyses of the recent aerosol body, though various questions on the air/ice transfer of major organic species need to be tackled as well.

\section{Acknowledgments}

This work was supported by the EU-project CARBOSOL (EVK2 CT2001-00113). We acknowledge the helpful comments of the two anonymous reviewers.

\section{References}

Bench, G. 2004. Measurement of contemporary and fossil carbon contents of $\mathrm{PM}_{2.5}$ aerosols: results from Turtleback Dome, Yosemite National Park. Environ. Sci. Tech. 38, 2424-2427. 
Bond, T. C., Streets, D. G., Yarber, K. F., Nelson, S. M., Woo, J.-H. and co-authors. 2004. A technology-based global inventory of black and organic carbon emissions from combustion. J. Geophys. Res. 109, 2003JD003697.

Carcaillet, C., Almquist, H., Asnong, H., Bradshaw, R. H. W., Carrión, J. S., and co-authors. 2002. Holocene biomass burning and global dynamics of the carbon cycle. Chemosphere 49, 845-863.

Currie, L. A., Klouda, G. A., Continetti, R. E., Kaplan, I. R., Wong, W. W., and co-authors. 1983. On the origin of carbonaceous particles in American cities: results of radiocarbon "dating" and chemical characterization. Radiocarbon 25, 603-614.

Currie, L. A., Fletcher, R. A. and Klouda, G. A. 1989. Source apportionment of individual carbonaceous particles using ${ }^{4} \mathrm{C}$ and laser microprobe mass spectrometry. Aerosol Sci. Tech. 10, 370-378.

Fagerli, H., Legrand, M., Preunkert, S., Simpson, D., Vestreng, V. and co-authors. 2007. Modeling historical long-term trends of sulfate, ammonium, and elemental carbon over Europe: a comparison with ice core records in the Alps. J. Geophys. Res. 112, 2006JD008044.

Fischer, H., Wagenbach, D. and Kipfstuhl, J. 1998. Sulfate and nitrate firn concentrations on the Greenland ice sheet, 2: temporal anthropogenic deposition changes. J. Geophys. Res. 103, 1998JD01886.

Gelencsér, A., May, B., Simpson, D., Sánchez-Ochoa, A., Caseiro, A., and 2007. Source apportionment of PM2.5 organic aerosol over Europe: primary/secondary, natural/anthropogenic, fossil/biogenic origin. J. Geophys. Res. 112, 2006JD008094.

Hammer, S., Wagenbach, D., Preunkert, S., Pio, C., Schlosser, C., and co-authors. 2007. ${ }^{210} \mathrm{~Pb}$ observations within CARBOSOL: a diagnostic tool for assessing the spatio-temporal variability of related chemical aerosol species?. J. Geophys. Res. 112, 2006JD008065.

Hildemann, L. M., Klinedinst, D. B., Klouda, G. A., Currie, L. A. and Cass, G. R. 1994. Sources of urban contemporary carbon aerosol. Environ. Sci. Tech. 28, 1565-1576.

Jenk, T. M., Szidat, S., Schwikowski, M., Gäggler, H. W., Brütsch, S., and co-authors. 2006. Radiocarbon analysis in an Alpine ice core: record of anthropogenic and biogenic contributions to carbonaceous aerosols in the past (1650-1940). Atmos. Chem. Phys. 6, 53815390.

Kanakidou, M., Tsigaridis, K., Dentener, F. J. and Crutzen, P. J. 2000. Human-activity-enhanced formation of organic aerosols by biogenic hydrocarbon oxidation. J. Geophys. Res. 105, 1999JD901148.

Klinedinst, D. B. and Currie, L. A. 1999. Direct quantification of $\mathrm{PM}_{2.5}$ fossil and biomass carbon within the Northern Front Range Air Quality study's domain. Environ. Sci. Tech. 33, 4146-4154.

Legrand, M. and Puxbaum, H. 2007. Summary of the CARBOSOL project: Present and retrospective state of organic versus inorganic aerosol over Europe. J. Geophys. Res. 112(D23), 2006JD008271.

Legrand, M., Preunkert, S., Schock, M., Cerqueira, M., Kasper-Giebl, A., and co-authors. 2007. Major 20th century changes of organic carbonaceous aerosol components (EC, WinOC, DOC, HULIS, carboxylic acids, and cellulose) derived from Alpine ice cores. J. Geophys. Res. 112, 2006JD008080.

Lemire, K. R., Allen, D. T., Klouda, G. A. and Lewis, C. W. 2002. Fine particulated matter source attribution for Southeast Texas using ${ }^{14} \mathrm{C} /{ }^{12} \mathrm{C}$ ratios. J. Geophys. Res. 107(D22) 2002JD002339.

Levin, I. and Kromer, B. 2004. The Tropospheric ${ }^{14} \mathrm{CO}_{2}$ level in MidLatitudes of the Northern Hemisphere (1959-2003). Radiocarbon 46, 1261-1272.
Lewis, C. W., Klouda, G. A. and Ellenson, W. D. 2004. Radiocarbon measurement of biogenic contribution to summertime PM-2.5 ambient aerosol in Nashville, TN. Atmos. Environ. 38, 6053-6061.

Limbeck, A., Kulmala, M. and Puxbaum, H. 2003. Secondary organic aerosol formation in the atmosphere via heterogeneous reaction of gaseous isoprene on acidic particles. Geophys. Res. Lett. 30(19), 2003 GL017738.

Liousse, C., Penner, J. E., Chuang, C., Walton, J. J., Eddleman, H., and co-authors. 1996. A global three-dimensional model study of carbonaceous aerosols. J. Geophys. Res. 101, 95JD03426.

Pio, C., Legrand, M., Oliveira, T., Afonso, J., Santos, C., and co-authors. 2007. Climatology of aerosol composition (organic versus inorganic) at non-urban areas on a West-East transect across Europe. J. Geophys. Res. 112, 2006JD008038.

Puxbaum, H., Caseiro, A. Sánchez-Ochoa, A., Kasper-Giebl, A., Claeys, M., and co-authors. 2007. Levoglucosan levels at background sites in Europe for assessing the impact of biomass combustion on the European aerosol background. J. Geophys. Res. 112, 2006JD008114.

Ramanathan, V., Crutzen, P. J., Kiehl, J. T. and Rosenfeld, D. 2001. Aerosols, Climate and the Hydrological Cycle. Science 294, 21192124.

Schichtel, B. A., Malm, W. C., Bench, G., Fallon, S., McDade, C. E., and co-authors. 1999. Levoglucosan, a tracer for cellulose in biomass burning and atmospheric particles. Atmos. Environ. 33, 173-182.

Simoneit, B. R. T., Schauer, J. J., Nolte, C. G., Oros, D. R., Elias, V. O., and co-authors. 1999. Levoglucosan, a tracer for cellulose in biomass burning and atmospheric particles. Atmos. Environ. 33, 173-182.

Steier, P., Drosg, R., Fedi, M., Kutschera, W., Schock, M., and coauthors. 2006. Radiocarbon determination of particulate organic carbon in glacier ice from the Grenzgletscher (Monte Rosa). Radiocarbon 48, 69-82.

Stocks, B. J., Mason, J. A., Todd, J. B., Bosch, E. M., Wotton, B. M., and co-authors. 2003. Large forest fires in Canada, 1959-1997. J. Geophys. Res. 108, 2001JD000484.

Stuiver, M. and Polach, A. 1977. Reporting of ${ }^{14} \mathrm{C}$ data. Radiocarbon 19, 355-363.

Szidat, S., Jenk, T. M., Gäggler, H. W., Synal, H.-A., Fisseha, R., and co-authors. 2004a. Radiocarbon-deduced biogenic and anthropogenic contributions to organic carbon (OC) of urban aerosols from Zürich, Switzerland. Atmos. Environ. 38, 4035-4044.

Szidat, S., Jenk, T. M., Gäggler, H. W., Synal, H.-A., Fisseha, R., and co-authors. 2004b. Source apportoinment of aerosols by ${ }^{14} \mathrm{C}$ measurements in different carbonaceous particle fractions. Radiocarbon 46(1), 475-484.

Szidat, S., Jenk, T. M., Synal, H.-A., Kalberer, K., Wacker, L., and co-authors. 2006. Contributions of fossil fuel, biomass-burning, and biogenic emissions to carbonaceous aerosols in Zurich as traced by ${ }^{14}$ C. J. Geophys. Res. 111(D7), 2005JD006590.

Szidat, S., Prévôt, A. S. H., Sandradewi, J., Alfarra, M. R., Synal, H.-A., and co-authors. 2007. Dominant impact of residential wood burning on particulate matter in Alpine valleys during winter. Geophys. Res. Lett. 34, 2006GL028325.

Tanner, R. L., Parkhurst, W. J. and McNichol, A. P. 2004. Fossil sources of ambient aerosol carbon based on ${ }^{14} \mathrm{C}$ measurements. Aerosol Sci. Tech. 38, 133-139.

Tsigaridis, K., Krol, M., Dentener, F. J., Balkanski, Y., Lathière, J., and co-authors. 2006. Change in global aerosol composition 
since preindustrial times. Atmos. Chem. Phys. 6, 51435162.

Vestreng, V., Myhre, G., Fagerli, H., Reis, S. and Tarrasón, L. 2007. Twenty-five years of continuous sulphur dioxide emission reduction in Europe. Atmos. Chem. Phys. 7, 3663-3681.

Ward, T. J., Rinehart, L. R. and Lange, T. 2006. The 2003/2004 Libby, Montana PM2.5 source apportionment research study. Aerosol Sci. Tech. 40(3), 166-177.
Zencak, Z., Elmquist M. and Gustafsson, O. 2007. Quantification and radiocarbon source apportoinment of black carbon in atmospheric aerosols using the CTO-375 method. Atmos. Environ. 41, 78957906.

Yalcin, K. and Wake, C. P. 2002. Anthropogenic signals recorded in an ice core from Eclipse Icefield, Yukon Territory, Canada. Geophys. Res. Lett. 28, 4487-4490. 